\title{
Perceiving emotion and sex from the body: evidence from the Garner task for independent processes
}

Gandolfo, Marco; Downing, Paul

\section{Cognition and Emotion}

DOI:

10.1080/02699931.2019.1634003

Published: 25/06/2019

Peer reviewed version

Cyswllt i'r cyhoeddiad / Link to publication

Dyfyniad o'r fersiwn a gyhoeddwyd / Citation for published version (APA):

Gandolfo, M., \& Downing, P. (2019). Perceiving emotion and sex from the body: evidence from the Garner task for independent processes. Cognition and Emotion.

https://doi.org/10.1080/02699931.2019.1634003

\footnotetext{
Hawliau Cyffredinol / General rights

Copyright and moral rights for the publications made accessible in the public portal are retained by the authors and/or other copyright owners and it is a condition of accessing publications that users recognise and abide by the legal requirements associated with these rights.

- Users may download and print one copy of any publication from the public portal for the purpose of private study or research.

- You may not further distribute the material or use it for any profit-making activity or commercial gain

- You may freely distribute the URL identifying the publication in the public portal?
}

Take down policy

If you believe that this document breaches copyright please contact us providing details, and we will remove access to the work immediately and investigate your claim. 
Perceiving emotion and sex from the body:

Evidence from the Garner task for independent processes

\author{
Marco Gandolfo* \\ Paul E. Downing
}

School of Psychology

Bangor University

Bangor, Gwynedd, LL57 2DG

United Kingdom

*Corresponding author: m.gandolfo@ bangor.ac.uk or marco2gandolfo@gmail.com

Figures: 2

Tables: 1

Supplementary Figures: 1

Keywords: emotional body expression, sex, body posture, body shape, attention, interference 


\begin{abstract}
The appearance of the body signals socially relevant states and traits, but the how these cues are perceived is not well understood. Here we examined judgments of emotion and sex from the body's appearance. Understanding how we extract these cues is important because they are both salient and socially relevant. Participants viewed body images and either reported the emotion expressed by each body while ignoring its sex, or else reported the sex while ignoring its emotion. Following Garner's logic (1974), two types of blocks were compared. In control blocks, the taskirrelevant dimension was fixed (e.g. all male in an emotion judgment task), whereas in orthogonal blocks it varied orthogonally to the task-relevant dimension (e.g. male-female). Where two dimensions draw on shared processes, interference results in relatively slower responses during orthogonal blocks. In contrast, a finding of no Garner interference -efficient selection of the taskrelevant dimension- is taken to reflect independent processes. Bayesian analyses revealed evidence of no Garner interference between sex and emotion judgments, showing that extraction of these distinct signals from the body's appearance proceeds along largely parallel processing streams. These findings are informative about the mental architecture behind our perception of socially relevant characteristics of other people.
\end{abstract}


From a mere glimpse, we make inferences about other people based on their visual appearance, and these inferences shape our social behaviour (Adams et al., 2011). To date, the major focus in the field of "social vision" has been on face perception, leading to a generally accepted model of face processing (Bruce and Young, 1986; Haxby et al., 2000; Duchaine and Yovel, 2015). There is also strong evidence that the visual appearance of the rest of the body provides a rich source of socially relevant cues (Aviezer et al., 2012; de Gelder, 2009; Johnson et al., 2012; Knoblich et al., 2006; Lawson et al., 2009; Rosenthal et al., 1979; Rice et al., 2013; Sell et al., 2009). Yet we remain some distance from establishing a "standard" model of body perception. Analogies from faces to bodies are likely to be imperfect given the significant perceptual differences between these two classes. However, the diversity of experimental approaches that has been used to carve up the processes of face perception can be extended to learn more about how we see bodies. In that spirit, here we used a selective-attention task to understand how representations of bodies are organised to support inferences about the sex and the emotional states of others.

There are strong a priori reasons to expect that body cues to sex should be highly salient for observers, given the clear biological and social relevance of this property. For example, adult observers are finely attuned to the shape differences that distinguish adult male from female body forms (Gaetano et al., 2014; Gandolfo and Downing, in review; Johnson and Tassinary, 2005) suggesting that this is a key dimension of the mental "spaces" that describe body shape (Palumbo et al., 2013). Further, discrimination of sex from static body images begins to develop in infants as early as 5 months of age (Hock et al., 2015) with continued refinement during childhood (Johnson, Lurye, and Tassinary, 2010). It is likewise understood that body cues to emotion are salient, given the high value of these signals to an observer (de Gelder, 2016). There is evidence for efficient extraction of emotional content from body postures (Martinez et al., 2016; Meeren et al., 2005) with a strong impact on spatial orienting as measured, for example, with saccade latencies (Bannerman et al., 2009) or by the influence of emotional body states on spatial neglect (Tamietto et al., 2007). Further, sensitivity to body shape and motion cues about emotions develops within the first few months of life (Bhatt et al., 2016). These kinds of evidence suggest that the need to perceive the sex and emotions of other people strongly influences the way bodies are mentally encoded.

Additionally, there are good reasons to expect that the processes behind perceiving sex and emotion may be intertwined. For one, at a perceptual level, there is evidence that the visual cues to sex and to emotion of faces are at least in part shared with each other (Becker et al., 2007; Bestelmeyer et al., 2010; Harris and Ciaramitaro, 2016; Hess et al., 2009) leading to behavioural interactions. For example, Bestelmeyer et al. (2010) found evidence for sex-contingent aftereffects following adaptation to facial emotion expressions of anger and fear. Furthermore, current 
dynamical views of social cognition and perception emphasize continuous interaction between bottom-up visual cues from social stimuli such as faces and bodies, and top-down social-cognitive processes related to categorical, associative, and contextual influences (Freeman and Ambady, 2011; Freeman and Johnson, 2016). In the specific case of sex and emotion, for example, strong cultural associations link femininity with a more intense experience and expression of emotion, and link masculinity with anger and pride (Becker et al., 2007; Kite et al., 2008; Plant et al., 2000). In line with an interactive view, then, these associations may in turn shape and influence "lower level" perceptual processes. Such interactions play out in evidence that observers' evaluation of emotional expressions can be coloured by their understanding of the sex of the model (Condry and Condry, 1976; Haugh et al., 1980), and conversely, that emotional facial expressions bias the evaluation of sex (Bayet et al., 2015). More recently, a similar interaction has been observed for body perception, in that emotional expression judgments are biased by the sex of the model, often in a stereotypical direction (e.g. female = positive emotion; Bijlstra et al., 2018).

Taken together, the preceding considerations motivated the present study, which examined whether visual representations of sex and emotion from the body are independent to each other proceeding along different processing "channels" - or rather instead are functionally integrated. Specifically, we adapted the Garner selective attention task, which has provided an important tool for establishing the independence or otherwise of perceptual processes (Algom and Fitousi, 2016; Garner, 1974). In such tasks, participants are required to classify exemplars of a stimulus along a particular dimension (e.g. shape) while a second, task-irrelevant dimension of the stimulus (e.g. colour) is either held constant or is varied. Performance (in terms of response times) is typically compared in two key conditions. In a "control" condition, the irrelevant dimension is kept stable (e.g. squares and rectangles all shown in red). In an "orthogonal" condition, the irrelevant dimension varies orthogonally across trials (e.g. squares and rectangles in either red or blue). A relative increase in response times in the orthogonal condition indicates that participants cannot fully filter out the irrelevant dimension (in this example, colour) while attending to the shape information. The logic in this case is that perception of the two dimensions is at least partly integral - that is, reliant on shared perceptual processes. Conversely, if no impairment in the orthogonal condition is found, the two dimensions of the stimulus are considered to be processed independently.

The Garner logic has been applied to test perception of properties carried by the appearance of the face such as sex, identity and expression (Amishav and Kimchi, 2010; Ganel and GoshenGottstein 2002; 2004; Schweinberger and Soukoup, 1998; Schweinberger et al., 1999). For example, Ganel and Goshen-Gottstein (2002) found evidence for integral processing of face identity 
and sex, in support of a shared- rather than independent-route hypothesis. Such findings demonstrate the utility of selective attention tasks to test the processing architecture of complex, meaningful stimuli in addition to the more elemental perceptual dimensions tested in earlier work.

More recently, Johnstone and Downing (2017; see also Reed et al., 2018) reported the first application of the Garner approach to body perception. They investigated two socially-relevant properties that are conveyed by body shape: sex and weight. They found that irrelevant variation of sex interfered with weight judgments, but irrelevant variation of weight did not interfere with sex judgments. One interpretation of this asymmetrical pattern of interference is that it reflects a parallel contingent system (cf. Turvey, 1973). That is, parallel processes analyse features of body shape related to sex and to weight, and initial results of sex categorisation impact the processing of weight (but not vice versa). This architecture may relate to the distinct impacts of weight gain/loss on body shape for males and for females. These findings illustrate the potential of the Garner approach for dissecting the visual perception of the body.

In the present study, we adopted Garner's approach to examine the perception of sex and emotional states from others' bodies. The emotional expressions we tested were drawn from some of the canonical emotion categories that have been extensively explored in studies of face and body emotional expression: anger, fearful, happy, sad. These were paired arbitrarily so that each emotion task would require a binary judgment comparable to the sex task. Hence over three experiments, we asked participants to perform a sex judgment (male/female) and, in separate blocks, an emotion judgment (Experiment 1: angry/fearful; Experiment 2: angry/happy; Experiment 3: happy/sad). The judgments were performed on images of real human bodies, which, crucially, were the same in both tasks. In line with the Garner logic, participants performed the tasks in Control blocks (in which the irrelevant dimension was held constant) and in Orthogonal blocks (in which the irrelevant dimension was varied orthogonally). If accurate response times are found to be slower in the Orthogonal condition, this would provide evidence for shared representations underlying the extraction of sex and emotion from the appearance of the body. In contrast, if performance is unhindered by variation in the irrelevant dimensions, this indicates that these social cues are perceptually extracted by independent processes.

\section{Methods}

\section{Participants}

Participants in each experiment were 32 students at Bangor University. Sample size was informally determined a priori with reference to similar previous studies (e.g. Johnstone and Downing, 2017). No participant took part in more than one of the experiments. They took part in 
return for course credit in a research methods module, and provided informed consent to participate. Gender ratios and age ranges are reported below with the results of each experiment. The experimental procedures were approved by the Research Ethics Committee of Bangor University's School of Psychology.

\section{Stimuli}

Digital photographs of 8 different actors ( 4 males, 4 females) performing 4 different emotional expressions (anger, fear, happy, sad) were captured against a neutral background. Each actor wore a white t-shirt and blue jeans. Actors were instructed to express the emotions using their whole body and to avoid raising their hands and arms above the head or in front of the face. They were not discouraged from expressing the emotion with the face, although they were aware that the face would be obscured in the resulting image. Images were re-scaled from their original raw size to be 450 x 450 pixels (approximately $13 \times 13 \mathrm{~cm}$ onscreen) and converted to grayscale. In each image, the face and head were covered with a mosaic mask using Photoshop (Adobe Inc.). Feet were cropped from the images given that (unlike clothing) shoe type and colour were not held constant across models. A total of 148 images were collected in the initial stimulus-creation phase. Using Google Forms (Google Inc.), we then collected online ratings data from 25 participants regarding these images. These participants were asked to categorise which emotion was expressed in each image, by choosing between "Angry", "Happy", "Sad”, "Fear" or "Other”. They were also asked for each image how intense and how realistic the emotion expression was, on a Likert scale from 1 to 5. For each emotion and each actor, we selected the most accurately identified images, with the result that all selected images were classified with above $90 \%$ mean accuracy. We then selected, for each emotion $\mathrm{x}$ sex $\mathrm{x}$ actor combination, the image with the best combined rating for realism and intensity. The final set of stimuli comprised 8 pictures for each emotion. Sample images are shown in Figure 1. The full set is shown in Supplementary Figure 1.

\section{Design and Procedure}

Two speeded binary classification tasks were performed by each participant. In each experiment, 16 participants first performed an emotion judgement task (for example, Anger vs Fear), and 16 performed a sex judgement task first. Task order was assigned on the basis of registration for the study. To counteract carryover effects, for each task, the Control and Orthogonal blocks were presented in a counterbalanced order across participants. Two versions of each Control condition were tested, to include trials for each level of the irrelevant dimension. For example, in the Angry vs Fear task, in one Control block the images were all of females, and in the other all 
males. These blocks were presented in counterbalanced order across participants. Continuing the example, in the Orthogonal block, the images would be a mixture of males and females. Each Control block comprised 64 trials, and the Orthogonal block comprised 128 trials. Block structure was not made explicit to the participants, in order to avoid drawing their attention to changes in the irrelevant stimulus dimensions. Participants had a break between the two classification tasks.

The experiment was administered using the Psychtoolbox (Brainard, 1997) package running in Matlab (MATLAB Release 2012b, The MathWorks, Inc.) on an Apple iMac computer. Viewing distance was approximately $60 \mathrm{~cm}$ from the screen but was not fixed. In each trial, following a 300 ms fixation dot, a single stimulus was presented at the centre of the screen, where it remained until the participant responded or until a maximum duration of $1.5 \mathrm{sec}$. Participants' responses were recorded with the "f" and " $\mathrm{j}$ " keyboard keys to report either the sex or the emotion of the body. They were reminded of the response mapping with the corresponding category names printed at the bottom of the screen. Participants were instructed to respond as quickly and as accurately as possible.

\section{Analyses}

Two separate ANOVAs were conducted on the response time and accuracy data, respectively, from each experiment: these took the form of 2 (Task: Sex or Emotion) X 2 (Block: Control or Orthogonal) repeated measures factorials. For the response time analysis, only data from accurate trials were included. Data from participants whose overall accuracy was < 2.5 SD below the group mean, or whose mean response times were >2.5 SD above or below the group mean, were removed and new participants were tested to bring the $\mathrm{N}$ up to 32 .

Following the logic of the Garner selective attention task, the absence of interference (no difference in response times between Orthogonal and Control blocks) can be considered as positive evidence for independent processing of the two dimensions in question. Accordingly, here we complemented the null hypothesis significance testing approach with a Bayesian inference approach in order to assess to what extent our findings evidence the independence of processing sex and emotion from the body. To do this, we computed Garner interference indexes for each participant (mean accurate response time for Orthogonal - mean accurate response time for Control condition) and performed one sample t-tests against 0 (i.e. absence of Garner interference). Bayes Factors (BF) were computed over these values using Jasp (Jasp software; https://jasp-stats.org/) (Love et al., 2015). We considered findings of $\mathrm{BF}_{10}$ lower than $1 / 3$ (Jeffrys, 1961; Lee and Wagenmakers, 2014) as moderate or better evidence for independent processing of the two dimensions. Results for all three experiments are shown in Figure 2 and provided numerically in Table 1. 


\section{Results}

\section{Experiment 1: Angry and Fearful}

Participants in Experiment 1 consisted of 27 females and 5 males, with a mean age of $19 \pm$ 2.2 years. Data from 1 participant were excluded from the analysis due to poor performance and were replaced.

The ANOVA on accuracy did not reveal any significant effects (all $p$ s $>0.11$ ). The ANOVA on response times showed a significant main effect of Task, $\mathrm{F}(1,31)=23.41, p<0.001, \eta^{2}=0.43$. Discrimination of sex was faster $(M=621 \mathrm{~ms}, \mathrm{SE}=14.1)$ than of emotional postures $(\mathrm{M}=669 \mathrm{~ms}$, $\mathrm{SE}=14.5)$. No other effect reached significance (all $p>0.55)$.

A Bayesian one sample t-test on Garner interference indexes showed moderate evidence for the absence of Garner interference both in the sex task $\left(\mathrm{BF}_{10}=0.21\right)$ and in the emotion task $\left(\mathrm{BF}_{10}\right.$ $=0.21$ ) in the sense that the null hypothesis is at least three times more likely than the alternative.

\section{Experiment 2: Happy and Angry}

Participants in Experiment 2 consisted of 26 females and 6 males, with a mean age of $19 \pm$ 1.1 years. Data from 3 participants were excluded from the analysis due to poor performance and were replaced.

The ANOVA on accuracy showed a main effect of Task, $\mathrm{F}(1,31)=9.92, p<0.001, \eta^{2}=$ 0.46. Participants were more accurate in classifying sex $(M=0.93, S E=0.01)$ than emotion $(M=$ $0.87, \mathrm{SE}=0.009)$. No other effect reached significance (all $p>0.66$ ).

The ANOVA on response times showed a main effect of Task, $\mathrm{F}(1,31)=32.27, p<0.001$, $\eta^{2}=0.51$. Participants were faster in classifying sex $(M=609 \mathrm{~ms}, \mathrm{SE}=12.1)$ than emotion $(\mathrm{M}=$ $668 \mathrm{~ms}, \mathrm{SE}=16.4)$. No other effect reached significance (all $p \mathrm{~s}>0.17$ ).

A Bayesian one sample t-test on Garner interference indexes showed moderate evidence in the sex task $\left(\mathrm{BF}_{10}=0.19\right)$ and anecdotal evidence in the emotion task $\left(\mathrm{BF}_{10}=0.63\right)$ for the absence of Garner interference.

\section{Experiment 3: Happy and Sad}

Participants in Experiment 3 consisted of 28 females and 4 males, with a mean age of $19 \pm 1$ years. Data from 2 participants were excluded from the analysis due to poor performance and were replaced.

The ANOVA on accuracy did not reveal any significant effects (all $p>0.15$ ). The ANOVA on response times likewise did not reveal any significant effects (all $p>0.38$ ). 
A Bayesian one sample t-test on Garner Interference indexes showed moderate evidence for the absence of Garner interference both in the sex task $\left(\mathrm{BF}_{10}=0.19\right)$ and in the emotion task $\left(\mathrm{BF}_{10}\right.$ $=0.33$ ) in the sense that the null hypothesis is at least three times more likely than the alternative.

\section{General Discussion}

Over three experiments, participants were able to successfully filter irrelevant variation in sex when judging bodily emotion, and vice versa. Broadly, this finding held across three different pairings of four different emotion categories. We take this as evidence for independent processes that support perceiving sex and emotion from body shape and posture.

Sex is generally considered to be one of the primary dimensions that perceivers establish upon encountering another individual (Stangor et al., 1992). Yet in the present study, participants were able to ignore this dimension successfully, with no detectable cost to performance on another body-related task. Some trivial accounts of this finding can be excluded. While the body images were constructed so that extraneous cues (face, clothing type) were obscured or controlled, this did not render the sex judgment task particularly difficult, as evidenced by the response time and accuracy data. This suggests that the absence of Garner interference from sex on the emotion task is not due to variation between sexes being minimized. Further, as the images were presented individually in the absence of other visual distractors, there was little perceptual load that might have interfered with extracting sex-related cues (Lavie, 1995).

The logic of interpreting interference effects depends on the relative baseline difficulty of the two discriminations being approximately equivalent. In the case that one task is much more difficult than the other, it can be trivial that the more difficult dimension does not interfere with the easier one. In the present study, overall task difficulty was not always perfectly matched. In Experiment 1, participants' discrimination of sex was faster (but no more accurate) than for emotion; in Experiment 2, the sex task was faster and more accurate. Note, however, that an easier sex task would predict that this dimension is more readily encoded than emotion, and hence if anything more likely to create interference in the Orthogonal condition. Yet no such interference was observed in those experiments, nor in Experiment 3 in which task difficulty was matched by both accuracy and response time measures.

As for sex, previous evidence has been mustered to argue that the body is a key signaller of emotions (Aviezer et al., 2012; de Gelder, 2016), and that such signals exert a powerful force on early perceptual processes (e.g. Tamietto et al., 2007; 2009). Yet in the present study, irrelevant variation in bodily emotion did not intefere with making sex judgements. One possibility is that the stimuli did not strongly convey the emotions that they were designed to convey, and/or did not do 
so realistically. Our stimulus design procedure and our results provide assurance against the first concern. Performance on the emotion tasks was fast and accurate, showing that participants were readily able to make these discriminations. Further, the images were selected based on independent observers' ratings of the strength and clarity of the emotional expression they conveyed. Whether these instructed poses are realistic expressions of emotion - whether in daily life people spontaneously take these postures when happy, sad, etc. - is a separate concern, one that applies to all of the previous work on emotional body expression that uses posed expressions as stimuli. We do note that the stimuli used here were static images rather than dynamic displays, and it is possible that the salience or psychological validity of the emotions would be greater in movies (Peelen et al., 2007; Pichon et al., 2008).

As we used real human actors to generate our stimuli (as opposed to rendered images), we cannot exclude the possibility that male and female models differed systematically in the specifics of how they expressed a given emotion through posture. In other words, it is possible that the two dimensions tested here were in some sense entangled in the stimulus. However, such a confounding factor, if present and detectable by participants, would have been expected to produce Garner interference, which we did not observe.

Having excluded more trivial accounts of the present findings, it remains the case that arriving at a conclusion of independent processes depends on interpreting a null effect (that is, no difference between Control and Orthogonal blocks). This is a common feature of any application of the Garner paradigm. To this end, we applied Bayesian analyses in order to arrive at positive statements about the likelihood, given the data, of no Garner interference being present. Taken together, the present evidence shows that if Garner interference between sex and emotion in bodies exists, the true effect size is likely to be small.

How do the present findings compare with evidence on face perception? Previous studies have compared sex and emotion in faces with the Garner task, with varying results. Le Gal and Bruce (2002) found that angry / surprised facial expressions and sex were independently processed (i.e. no Garner interference) when the discriminability of the sex and emotion judgements were matched. In contrast, Atkinson et al. (2005) found an asymmetric interference pattern: the irrelevant variation of sex interfered with happiness / fear expression judgments, but irrelevant variation of emotion did not interfere with sex judgements. They interpreted their finding by proposing that invariant dimensions of a person (sex) are more useful referents for computing information about variant aspects (emotional expression) than vice versa. More recently, Becker (2017) found asymmetric interference between emotion (anger, happiness) and sex, that further depended on individual differences in attentional control capacities. In future work, it would be useful to directly 
compare selective attention for faces and bodies in the same participants with matched designs and stimuli (including emotion categories), to better establish the commonalities and distinctions across these domains. Interestingly, the Garner approach has also provided evidence for the impact of mental health on the ability to attend or ignore emotional content. Gilboa-Schechtman et al. (2004) found that participants with depression were less able than controls to ignore emotional face content, relative to sex, in a Garner task.

How does the evidence for independent analysis of sex and emotion from the body relate to our understanding of the relevant neural systems? The last few decades have seen much new evidence on the location and properties of regions across the brain that are engaged in some way by the appearance of bodies and their movements (Bradman and Yovel, 2014; de Gelder 2006; Downing and Peelen, 2011, 2016; Minnebusch and Daum, 2009; Peelen and Downing, 2007; Schwoebel and Coslett, 2005). Whilst there has been significant interest in how these regions encode emotional expressions of the body (de Gelder, 2009; Peelen et al., 2007), little direct evidence exists on how they are involved in distinguishing the sexes. Nonetheless we can speculate about three possible scenarios linking brain and behaviour.

Two scenarios focus on cortical pathways. One view draws a distinction between the focal and selective brain representations of the body found in the ventral and dorsal temporal lobe regions. Ventrally, the extrastriate body area (EBA: Downing et al., 2001) and fusiform body area (FBA: Schwarzlose et al., 2005; Peelen and Downing, 2005) are engaged by static aspects of the body (e.g. shape), while dorsal regions (e.g. posterior superior temporal sulcus, pSTS) are enagaged by dynamic displays of movements and meaningful actions (Downing et al., 2006; Giese and Poggio, 2003; Urgesi et al., 2007). Whilst the stimuli tested here were static, the emotional expressions could invoke a dynamic representation (e.g. by association with known movement patterns). In this case, we might relate the two independent processes identified here to engagement of the ventral (sex) and dorsal (emotion) pathways.

A second cortical view focuses within the ventral body-selective regions. Downing and Peelen (2011) surveyed neuroimaging findings to conclude that EBA and FBA jointly encode the shape and the posture of viewed bodies. Part of this conclusion was supported by evidence for encoding of emotion from body postures in the activity of EBA and FBA (Peelen et al., 2007; Atkinson et al., 2012; but see van de Riet et al., 2009). In this light, the present findings could reflect parallel processes that are spatially co-localised within these ventral regions, that represent our implicit knowledge of both the shape "space" that characterises different sexes, and also the postural representations that relate to different emotional states. 
In contrast to the above perspectives, a third possible account (cf. de Gelder, 2006) emphasises the role of subcortical regions such as the amygdala in a rapid, automatic evaluation of bodily emotions, in particular those that might naturally evoke an overt response on the part of the observer (such as a defensive response elicited by fear). On this view, a subcortical process may work in tandem with cortical body-selective regions where a richer visual analysis of bodily expression is required, such as where finer verbalizable judgments about the emotions being expressed are needed. If this hypothesised pathway uniquely analyses emotion and does not extend to include processing of sex from body shape, then it offers another means by which these two body dimensions may be analysed independently. Adapting the Garner logic developed here to a functional neuroimaging design may help distinguish amongst these alternative accounts.

Finally, one limitation of the present study is that our sample was biased strongly in favour of female over male participants, precluding a systematic examination of the effect of participant gender on attention to sex and emotion. While there is not evidence to suggest an impact of observer gender on the independence of these two dimensions per se, there is active research on the influence of gender on the perception of socially relevant cues from faces and from bodies alike, with both positive and negative findings (e.g. Grimshaw et al., 2004; Kret and de Gelder, 2012; McBain et al., 2009; Montagne et al., 2005). Accordingly, future examinations of social cue processing from bodies should balance, and test for interactions with, participant gender.

\section{Concluding remarks}

While the discipline of social vision remains largely focused on face perception, there is increasing awareness of the need to better understand body perception. More broadly, a fuller understanding of person perception (from faces, bodies, and voices alike) contributes to the effort to draw together insights from perception with those from social psychology for a multi-level understanding of how we understand and interact with the social world (Freeman and Ambady, 2011). 


\section{References}

Adams Jr, R. B., Adams, R. B., Ambady, N., Shimojo, S., \& Nakayama, K. (Eds.). (2011). The Science of Social Vision: The Science of Social Vision (Vol. 7). Oxford University Press.

Amishav, R., \& Kimchi, R. (2010). Perceptual integrality of componential and configural information in faces. Psychonomic Bulletin \& Review, 17(5), 743-748.

Algom, D., \& Fitousi, D. (2016). Half a century of research on Garner interference and the separability-integrality distinction. Psychological Bulletin, 142(12), 1352.

Atkinson, A. P., Tipples, J., Burt, D. M., \& Young, A. W. (2005). Asymmetric interference between sex and emotion in face perception. Perception \& Psychophysics, 67(7), 1199-1213.

Atkinson, A. P., Vuong, Q. C., \& Smithson, H. E. (2012). Modulation of the face-and bodyselective visual regions by the motion and emotion of point-light face and body stimuli. NeuroImage, 59(2), 1700-1712.

Aviezer, H., Trope, Y., \& Todorov, A. (2012). Body cues, not facial expressions, discriminate between intense positive and negative emotions. Science, 338(6111), 1225-1229.

Bannerman, R. L., Milders, M., De Gelder, B., \& Sahraie, A. (2009). Orienting to threat: faster localization of fearful facial expressions and body postures revealed by saccadic eye movements. Proceedings of the Royal Society of London B: Biological Sciences, rspb-2008.

Bayet, L., Pascalis, O., Quinn, P. C., Lee, K., Gentaz, É., \& Tanaka, J. W. (2015). Angry facial expressions bias gender categorization in children and adults: behavioral and computational evidence. Frontiers in psychology, 6, 346.

Becker, D. V. (2017). Facial gender interferes with decisions about facial expressions of anger and happiness. Journal of Experimental Psychology: General, 146(4), 457.

Becker, D. V., Kenrick, D. T., Neuberg, S. L., Blackwell, K. C., \& Smith, D. M. (2007). The confounded nature of angry men and happy women. Journal of personality and social psychology, 92(2), 179.

Bestelmeyer, P. E., Jones, B. C., DeBruine, L. M., Little, A. C., \& Welling, L. L. (2010). Face aftereffects suggest interdependent processing of expression and sex and of expression and race. Visual Cognition, 18(2), 255-274.

Bhatt, R. S., Hock, A., White, H., Jubran, R., \& Galati, A. (2016). The development of body structure knowledge in infancy. Child development perspectives, 10(1), 45-52.

Bijlstra, G., Holland, R. W., Dotsch, R., \& Wigboldus, D. H. (2018). Stereotypes and prejudice affect the recognition of emotional body postures. Emotion.

Brainard, D. H., \& Vision, S. (1997). The psychophysics toolbox. Spatial vision, 10, 433-436.

Brandman, T., \& Yovel, G. (2014). Bodies are represented as wholes rather than their sum of parts in the occipital-temporal cortex. Cerebral Cortex, 26(2), 530-543.

Bruce, V., \& Young, A. (1986). Understanding face recognition. British journal of psychology, 77(3), 305-327.

Condry, J., \& Condry, S. (1976). Sex differences: A study of the eye of the beholder. Child development, 812-819. 
Downing, P. E., Jiang, Y., Shuman, M., \& Kanwisher, N. (2001). A cortical area selective for visual processing of the human body. Science, 293(5539), 2470-2473.

Downing, P. E., Peelen, M. V., Wiggett, A. J., \& Tew, B. D. (2006). The role of the extrastriate body area in action perception. Social Neuroscience, , 1(1), 52-62.

Downing, P. E., \& Peelen, M. V. (2011). The role of occipitotemporal body-selective regions in person perception. Cognitive neuroscience, 2(3-4), 186.

Downing, P. E., \& Peelen, M. V. (2016). Body selectivity in occipitotemporal cortex: Causal evidence. Neuropsychologia, 83, 138-148.

Duchaine, B., \& Yovel, G. (2015). A revised neural framework for face processing. Annual Review of Vision Science, 1, 393-416.

Freeman, J. B., \& Ambady, N. (2011). A dynamic interactive theory of person construal. Psychological review, 118(2), 247.

Freeman, J. B., \& Johnson, K. L. (2016). More than meets the eye: Split-second social perception. Trends in cognitive sciences, 20(5), 362-374.

Gaetano, J., van der Zwan, R., Blair, D., \& Brooks, A. (2014). Hands as sex cues: Sensitivity measures, male bias measures, and implications for sex perception mechanisms. PloS one, 9(3), e91032.

Ganel, T., \& Goshen-Gottstein, Y. (2004). Effects of familiarity on the perceptual integrality of the identity and expression of faces: the parallel-route hypothesis revisited. Journal of Experimental psychology: Human perception and Performance, 30(3), 583.

Ganel, T., \& Goshen-Gottstein, Y. (2002). Perceptual integrality of sex and identity of faces: Further evidence for the single-route hypothesis. Journal of Experimental Psychology: Human Perception and Performance, 28(4), 854.

Garner, W. R. (1974). The processing of information and structure. Lawrence Erlbaum Associates. de Gelder, B. (2016). Emotions and the Body. Oxford University Press.

de Gelder, B. (2009). Why bodies? Twelve reasons for including bodily expressions in affective neuroscience. Philosophical Transactions of the Royal Society B: Biological Sciences, 364(1535), 3475-3484.

de Gelder, B. (2006). Towards the neurobiology of emotional body language. Nature Reviews Neuroscience, 7(3), 242.

Giese, M. A., \& Poggio, T. (2003). Cognitive neuroscience: neural mechanisms for the recognition of biological movements. Nature Reviews Neuroscience, 4(3), 179.

Gilboa-Schechtman, E., Ben-Artzi, E., Jeczemien, P., Marom, S., \& Hermesh, H. (2004).

Depression impairs the ability to ignore the emotional aspects of facial expressions: Evidence from the Garner task. Cognition and Emotion, 18(2), 209-231.

Grimshaw, G. M., Bulman-Fleming, M. B., \& Ngo, C. (2004). A signal-detection analysis of sex differences in the perception of emotional faces. Brain and Cognition, 54(3), 248-250.

Harris, D. A., \& Ciaramitaro, V. M. (2016). Interdependent mechanisms for processing gender and emotion: the special status of angry male faces. Frontiers in psychology, 7, 1046. 
Haugh, S. S., Hoffman, C. D., \& Cowan, G. (1980). The eye of the very young beholder: Sex typing of infants by young children. Child development, 598-600.

Haxby, J. V., Hoffman, E. A., \& Gobbini, M. I. (2000). The distributed human neural system for face perception. Trends in cognitive sciences, 4(6), 223-233.

Hess, U., Adams, R. B., Grammer, K., \& Kleck, R. E. (2009). Face gender and emotion expression: Are angry women more like men?. Journal of Vision, 9(12), 19-19.

Hock, A., Kangas, A., Zieber, N., \& Bhatt, R. S. (2015). The development of sex category representation in infancy: Matching of faces and bodies. Developmental psychology, 51(3), 346.

Jeffreys, H. (1961). Theory of Probability: Oxford Univ. Press (earlier editions 1939, 1948).

Johnson, K. L., Lurye, L. E., \& Tassinary, L. G. (2010). Sex categorization among preschool children: Increasing utilization of sexually dimorphic cues. Child development, 81(5), 1346-1355.

Johnson, K., \& Shiffrar, M. (Eds.). (2012). People watching: Social, perceptual, and neurophysiological studies of body perception. Oxford University Press.

Johnson, K. L., \& Tassinary, L. G. (2005). Perceiving sex directly and indirectly: Meaning in motion and morphology. Psychological Science, 16(11), 890-897.

Johnstone, L. T., \& Downing, P. E. (2017). Dissecting the visual perception of body shape with the Garner selective attention paradigm. Visual Cognition, 25(4-6), 507-523.

Kite, M. E., Deaux, K., \& Haines, E. L. (2008). Gender stereotypes. Psychology of women: A handbook of issues and theories, 2, 205-236.

Knoblich, G. E., Thornton, I. M., Grosjean, M. E., \& Shiffrar, M. E. (2006). Human body perception from the inside out: Advances in visual cognition. Oxford University Press.

Kret, M. E., \& De Gelder, B. (2012). A review on sex differences in processing emotional signals. Neuropsychologia, 50(7), 1211-1221.

Lavie, N. (1995). Perceptual load as a necessary condition for selective attention. Journal of Experimental Psychology: Human perception and performance, 21(3), 451.

Lawson, R. P., Clifford, C. W., \& Calder, A. J. (2009). About turn: The visual representation of human body orientation revealed by adaptation. Psychological Science, 20(3), 363-371.

Le Gal, P. M., \& Bruce, V. (2002). Evaluating the independence of sex and expression in judgments of faces. Perception \& Psychophysics, 64(2), 230-243.

Lee, M. D., \& Wagenmakers, E. J. (2014). Bayesian cognitive modeling: A practical course. Cambridge university press.

Love, J., Selker, R., Marsman, M., Jamil, T., Dropmann, D., Verhagen, A. J., \& Wagenmakers, E. J. (2015). JASP (Version 0.7)[computer software]. Amsterdam, the netherlands: Jasp project.

Martinez, L., Falvello, V. B., Aviezer, H., \& Todorov, A. (2016). Contributions of facial expressions and body language to the rapid perception of dynamic emotions. Cognition and Emotion, 30(5), 939-952.

McBain, R., Norton, D., \& Chen, Y. (2009). Females excel at basic face perception. Acta psychologica, 130(2), 168-173. 
Meeren, H. K., van Heijnsbergen, C. C., \& de Gelder, B. (2005). Rapid perceptual integration of facial expression and emotional body language. Proceedings of the National Academy of Sciences, 102(45), 16518-16523.

Minnebusch, D. A., \& Daum, I. (2009). Neuropsychological mechanisms of visual face and body perception. Neuroscience \& Biobehavioral Reviews, 33(7), 1133-1144.

Montagne, B., Kessels, R. P., Frigerio, E., de Haan, E. H., \& Perrett, D. I. (2005). Sex differences in the perception of affective facial expressions: Do men really lack emotional sensitivity?. Cognitive processing, 6(2), 136-141.

Palumbo, R., Laeng, B., \& Tommasi, L. (2013). Gender-specific aftereffects following adaptation to silhouettes of human bodies. Visual Cognition, 21(1), 1-12.

Peelen, M. V., Atkinson, A. P., Andersson, F., \& Vuilleumier, P. (2007). Emotional modulation of body-selective visual areas. Social Cognitive and Affective Neuroscience, 2(4), 274-283.

Peelen, M. V., \& Downing, P. E. (2005). Selectivity for the human body in the fusiform gyrus. Journal of neurophysiology, 93(1), 603-608.

Peelen, M. V., \& Downing, P. E. (2007). The neural basis of visual body perception. Nature Reviews Neuroscience, 8(8), 636.

Pichon, S., de Gelder, B., \& Grezes, J. (2008). Emotional modulation of visual and motor areas by dynamic body expressions of anger. Social neuroscience, 3(3-4), 199-212.

Plant, E. A., Hyde, J. S., Keltner, D., \& Devine, P. G. (2000). The gender stereotyping of emotions. Psychology of Women Quarterly, 24(1), 81-92.

Reed, C. L., Bukach, C. M., Garber, M., \& McIntosh, D. N. (2018). It's Not All About the Face: Variability Reveals Asymmetric Obligatory Processing of Faces and Bodies in Whole-Body Contexts. Perception, 47(6), 626-646.

Rice, A., Phillips, P. J., Natu, V., An, X., \& O’Toole, A. J. (2013). Unaware person recognition from the body when face identification fails. Psychological Science, 24(11), 2235-2243.

van de Riet, W. A., Grèzes, J., \& de Gelder, B. (2009). Specific and common brain regions involved in the perception of faces and bodies and the representation of their emotional expressions. Social Neuroscience, 4(2), 101-120.

Rosenthal, R., Archer, D., Hall, J. A., DiMatteo, M. R., \& Rogers, P. L. (1979). Measuring sensitivity to nonverbal communication: The PONS test. In Nonverbal Behavior (pp. 67-98).

Schwarzlose, R. F., Baker, C. I., \& Kanwisher, N. (2005). Separate face and body selectivity on the fusiform gyrus. Journal of Neuroscience, 25(47), 11055-11059.

Schweinberger, S. R., \& Soukup, G. R. (1998). Asymmetric relationships among perceptions of facial identity, emotion, and facial speech. Journal of Experimental Psychology: Human perception and performance, 24(6), 1748.

Schweinberger, S. R., Burton, A. M., \& Kelly, S. W. (1999). Asymmetric dependencies in perceiving identity and emotion: Experiments with morphed faces. Perception \& Psychophysics, 61(6), 1102-1115.

Schwoebel, J., \& Coslett, H. B. (2005). Evidence for multiple, distinct representations of the human body. Journal of cognitive neuroscience, 17(4), 543-553. 
Sell, A., Cosmides, L., Tooby, J., Sznycer, D., von Rueden, C., \& Gurven, M. (2008). Human adaptations for the visual assessment of strength and fighting ability from the body and face. Proceedings of the Royal Society B: Biological Sciences, 276(1656), 575-584.

Stangor, C., Lynch, L., Duan, C., \& Glas, B. (1992). Categorization of individuals on the basis of multiple social features. Journal of Personality and Social Psychology, 62(2), 207.

Tamietto, M., Castelli, L., Vighetti, S., Perozzo, P., Geminiani, G., Weiskrantz, L., \& de Gelder, B. (2009). Unseen facial and bodily expressions trigger fast emotional reactions. Proceedings of the National Academy of Sciences, 106(42), 17661-17666.

Tamietto, M., Geminiani, G., Genero, R., \& de Gelder, B. (2007). Seeing fearful body language overcomes attentional deficits in patients with neglect. Journal of cognitive neuroscience, 19(3), 445-454.

Turvey, M. T. (1973). On peripheral and central processes in vision: Inferences from an information-processing analysis of masking with patterned stimuli. Psychological review, 80(1), 1.

Urgesi, C., Candidi, M., Ionta, S., \& Aglioti, S. M. (2007). Representation of body identity and body actions in extrastriate body area and ventral premotor cortex. Nature neuroscience, 10(1), 30. 
Body coding of emotion and sex 18

Acknowledgements.

We thank Simona Skripkauskaite and Julia Landsiedel for helpful comments on the manuscript. 